\title{
Rethinking the Optimal City Size from the Perspective of the City Network
}

\author{
Yuhong Cheng, Chujun Ma \\ School of Economics, Jinan University, Guangzhou, China \\ Email:sgcyh@163.com,machujun8051@163.com
}

How to cite this paper: Cheng, Y.H. and Ma, C.J. (2017) Rethinking the Optimal City Size from the Perspective of the City Network. Open Journal of Social Sciences, 5, 134-145.

https://doi.org/10.4236/jss.2017.55010

Received: March 27, 2017

Accepted: May 12, 2017

Published: May 15, 2017

Copyright @ 2017 by authors and Scientific Research Publishing Inc. This work is licensed under the Creative Commons Attribution International License (CC BY 4.0).

http://creativecommons.org/licenses/by/4.0/ (c) (i) Open Access

\begin{abstract}
The optimal city size is an intuitive and clear indicator of whether the current state of the city is efficient. So it is determined by the internal factors of the city and the way they are organized if the city operates as a container only. In the picture where the city network has become a normality of the existing economic organizations, the optimal city size theory, including the concept, the mechanism and the path need to be rethought. Therefore, this paper starts from the essential concept of optimal city size and analyzes the influences of urban network on urban production and internal attribute characteristics, and further briefly analyzes the influence path and mechanism of the urban network on the optimal city size.
\end{abstract}

\section{Keywords}

Optimal City Size, City Network, Urban Attribute

\section{Introduction}

The concept of the optimal city size has a long history. In early ages, it was only a kind of perceptually demographic depiction with the purpose of urban management and planning. After the middle of the 20th century, the "big city disease" problem which caused a fierce debate about the relationship between urban scale and urban efficiency started the economic analysis of the optimal city size problem with increasingly diverse perspectives.

As the basic problem of urban economics, the optimal city size has great significance to urban economic development and management. For a city, in what population size, it can always maintain a high efficiency? This is an unavoidable problem in the development of every city, and it is a question that has never really been clarified. The answer to this question involves another more important question. Is the city's efficiency only related to the size of the city? We do not in- 
tend to be entangled with these controversial issues because we believe that the reasons for the existence of the optimal size and the fulfillment of the conditions are more important than an exact number. This is why we want to continue this topic in the new urban environment.

The research on the optimal city size has experienced a transformation from analyzing the macro performance to investigating the micro mechanism. However, the changes have not broken through the framework of the monomer city which is considered as a container with all kinds of elements and sectors in it. And the external factors of the container are ignored. The neglect of the relationship between cities may not produce larger deviation on researching the mechanism of optimal city size in terms of the traditional development pattern of hierarchical and spatial expansion. However, in recent years, cities are gradually integrating with each other. They not only operate as containers, but define themselves as parts of the city network. Changes of circumstances and development mode of cities require reconsideration of the optimal city size theory, in order to find what have changed among the mechanism and factors of the optimal city size. What is particularly important is that we need to know the role of city network in these changes.

In this paper, through the review of the literature, the framework of the optimal city size is obtained. And in the study of the city network and its relationship with urban development, we can find the direct and potential relationship between city network and the optimal city size, so as to determine the mechanism of the optimal city size in the view of city network. So, the rest of the paper is structured as follows. Section 2 reviews the literatures about optimal city size and generalizes the essential connotation. Section 3 mainly analyzes the formation and characteristics of the city network, and then pictures the relationships between cities and the city network. As the core part of this article, Section 4 concretely demonstrates why and how city network influences the optimal size, and constructs a new research framework of the optimal city size under the perspective of the city network. Section 5 is conclusion and Section 6 is discussion, several specific and subtle issues are presented in this section.

\section{What Is the Optimal City Size?}

\subsection{Literature Review}

The concept of optimal city size is indefinite and is generally associated with the perspectives and methods of researchers. The most general definition is given by Henderson who defined the optimal city size as a scale maximizing the potential benefits of economic participants [1]. The potential benefits can be represented by net income of resident, gross output of a city or per capita output, and generally theoretic utility. That is to say, the optimal city size is an intuitive and comprehensive index of the efficiency of a city or a particular sector.

The urban economic theory has proved that the city size cannot be too small, but can be overlarge. But in the latter case, cities would remain in inefficient state. In the middle of the 20th century, the reason that the optimal city size 
problem became a hot spot was that some researchers expected to solve the inefficient state of the "city disease" by restricting the city size. Thus the optimal size was gained at the bottom point of the per capita cost curve of government public service. But the differences of the empirical results are very large, due to the diverse objects selected. And because of ignoring the private costs and diverse supplies [2], this view is not suitable to be the standard of the optimal city size research.

Criticized the theoretical and empirical defect of this view, Alonso put forward a seminal thought that the costs and the benefits were both related to the city size [3]. The optimal city size is achieved when the marginal benefit equals to the marginal cost. The cost-benefit method has become the basic approach of the optimal city size research and is widely used and continuously expanded. For example, based on the Cobb-Douglas production function and the neoclassical and endogenous growth model, Xiaolu and Xiaolin established a cost-benefit model composed of a benefit function and an external urban cost function. Their empirical result manifested that the optimal size of Chinese cities is the range of 500 thousands and 2 million [4]. Likely, Xiao-Ping got a conclusion that the optimal size of Tokyo is about 18 million [5].

The cost-benefit method particularly relies on the macro regularity of the relation between urban scale and urban cost-benefit. It emphasizes the practical conditions when the marginal benefit and the marginal cost get a state of balance. But it is not perfect because it lacks the analysis about the sources of the economies of scale and the diseconomies of scale. Also its framework is difficult to bring into the micro mechanism when it is applied to construct the theoretical and empirical model. Thus a problem is leaved, that is the city size becomes the only agent when analyzing efficiency. The functions of other elements, such as industrial structure, spatial structure, human capital, and immigration are regarded as uncorrelated or homogeneous. Another worrying problem is that the variety of empirical results based on this theory is incomparable because of wide differences in identifying the benefits and costs.

Another typical representative of the optimal city size theory is called Henry George Theorem (HGT). Simply, HGT states that when a city reaches its optimal size which means citizens get their maximal utilities through choosing public goods and private consumptions, the aggregate land rent equals to the total public expenditure [6] [7]. This theory explains the sources of the increasing to scale (like localization economies, urbanization economies) and decreasing to scale (like land scarcity, congestion) based on the theoretical assumptions of monocentric city [8]. Kanemoto, Ohkawara and Suzuki applied the theory to calculate the optimal size of Tokyo [9]. The HGT is also lack of micro mechanism in explaining why the optimal city size exists. And it is hard to transform the theory to an accurately empirical model under the strict assumptions.

Along with the development of economic theory, the new economic geography is widely used in this field for its strong explanatory power in the inner existence mechanism of the optimal city size. In simple terms, the theory states 
that the urban scale expansion is encouraged by agglomeration economy which is the primary cause of urban existence. But it is also limited by agglomeration diseconomy, such as congestion, increasing costs of living, environmental problems. The optimal city size is achieved when agglomeration economy and agglomeration diseconomy reach a balanced state. For example, Duranton and Puga got an equation of the optimal city size based on a model which synthesized congestion cost, urban specialization and agglomeration economy of sharing intermediate inputs [10]. The agglomeration theory of optimal city size develops a system of theoretical paradigm which combines the micro mechanism of agglomeration economy and the macro appearance of optimal size. It clarifies the relationship between the individual demand of welfare maximization and the gross net benefit maximization.

In general, the cognition about optimal size changes from concentrating on the outward appearances to digging the inner essence. This process manifests that the substantial mechanism of urban expansion and contraction is the foundation of the statistical regulation. Instead of contradictory, the optimality of individual and that of the whole city should be consistent.

\subsection{The Framework of the Optimal City Size}

There are two obscure problems waiting for further explanation. First, what is the exact concept or implication of the optimal city size? In the view of urban economics, the reason of the existence of optimal city size and the reason of the expansion or contraction of a city is consistent, namely efficiency. The optimal city size is an intuitive index of urban efficiency which is decided by urban attributive factors-agglomeration effect, industrial structure, infrastructure, government management, etc. - and how the system they constitute operates. That is to say, the optimal size will achieve when the city which operates as a system reaches maximal efficiency. So, what decide the optimal city size are these factors and the way of their cooperation. Even if the real sizes of different cities are same, their optimal sizes are different unless all of their sectors are exactly the same. An equation as follows can indicate this mechanism:

$$
N^{*}=A E_{1}^{\alpha_{1}} E_{2}^{\alpha_{2}} \cdots E_{m}^{\alpha_{m}}
$$

In Equation (1) $N^{*}$ represents the optimal city size, $E_{i}$ represents city's attributes and $\alpha_{i}$ is the coefficient of the influence of these attributes on the optimal city size, $A$ is a constant. Any change of the right variables will incur fluctuation of the optimal size.

Second, most papers of the optimal city size are based on the conventional notion of hierarchical paradigm which neglect the external influences through regarding cities as competitive containers that contain all kinds of factors. Obviously, this is a static disequilibrium thought of urban development. In fact, the city can't exist in isolation with regional economic. In the process of urban development, cities often play different roles and undertake different regional functions for their unique properties. And they form a system of regional divi- 
sion with other cities. The city size tends to balance under the dual urban relationship of competition and cooperation. It is dynamic. On the other hand, integration and regionalization that directly caused by multiple locations of multinational companies and spatial organizations have become the trend of the global economy. As chiefly spatial carriers for enterprises, cities have given rise to the formation of different levels of urban network. Cities, as nodes in the network, are directly involved in the formation and development of city network for their "container" functions, but also affected by the city network for their "node" functions. The dual attribute promotes continuous changes of urban structure and operation mode. Therefore, in the dynamic network circumstances, whether the meaning and the mechanism of optimal city size remain invariable? If not, what kind of role the urban network undertakes? These are going to be discussed in Section 4, but before that, clarifying the meaning of city network is necessary because it plays a key role in answering these questions.

\section{A Brief Description of City Network}

The traditional central place theory considers the relationship between cities is vertically hierarchical and unidirectional. The city that locates in the center of a region provides goods and services to the edge cities. The status of a city is determined by its location and properties. But in recent years, with the development of the deepening labor division and the continuous economic globalization which is incurred by division, the vertically hierarchical and unidirectional relationship between cities is moving towards the horizontal and bidirectional relationship of city network. Camagni, Stabilini and Diappi argued that the city network was a system formed by the horizontal relationship between professional centers [11]. Particularly, it has two types. One kind is the complementary network formed by professional centers that produce complementary products. It has a regional characteristic, such as polycentric urban system. The other category is the collaborative network formed by professional centers that produce similar products or have similar functions. They collaborate with each other is to obtain higher efficiency. The collaborative network has a global characteristic. This definition reveals the general outline of the city network. The commodity chain or the cooperative network weaves cities together. It indicates that cities are relatively equal to each other.

Furthermore, the formation of the horizontal relationship is the result of advanced producer service firms' commercial activities which produce and carry variety kinds of "flows", such as ideas, knowledge, information, personnel, etc. Meanwhile, the "flows" link different cities to a network. Advanced producer service firms choose those cities that have knowledgeable background to set up branches for the need of business expansion. Thus a global office network comes out in the form of providing services. It is the daily activities of these offices produce the "flows" that form a service network and interlock cities to the city network which has three levels: supranodal network level (city network), nodal level (cities) and subnodal level (advanced producer service firms) [12] [13] [14]. 
This is Taylor's interlocking network theory.

The realistic foundation of the interlocking network is globalization and diversification. As the two sides of the same coin, the world economy is moving toward globalization, integration and regionalization, decentralization. Empirical researches of the interlocking network also reflect that the global city network is not spatially homogeneous, but with regional characteristics [15] [16]. The regional production and service network is a part of the global economic network. It is the interlocking city network provides core knowledge elements for production and consumption [17]. It also connects the decentralized production and consumption to constitute the complete commodity chains. Thus, a relatively clear picture of urban network is depicted.

In the city network system, urban development is more and more influenced by the external relationship. Urban attributes and structure are changing under the influences of the city network. In turn, the status of the city in the network and the nodal function are also shaped by internal city structures. The system that consists of inside and outside city factors is the realistic foundation of the new paradigm of the optimal city size.

\section{A General Mechanism Analysis}

The optimal city size theory of the monomer city shows that the optimal city size is achieved when urban attributes at a certain point of time maximize the economic efficiency of a city or an economic sector. In this mechanism what plays a decisive role is the relative importance of each attribute. For example, the theory from the perspective of the new economic geography suggests that the developmental degree of agglomeration economy and agglomeration diseconomy is the main factor in determining the optimal city size. In the view of city network, the core mechanism of optimal city size has not changed, that is, the maximization of urban economic efficiency. When taking into account of the role of city network, the optimal city size is determined by the internal factors and the external network factor. The role of external features in the network depends on the way the city network participates in economy. Specifically, the influences of city network on the urban economy and the optimal size have the following aspects.

1) The impact on economic structure. The emergence of city network is based on the labor and intellectual division. Its formation and development make the division show the spatial characteristic of urban division. Because of the urban division, cities gradually behave as a whole in terms of economic organizations and space. This means that the development of the individual city not only depends on the ability to compete for resources elements, and more relies on the cooperation between cities and the city network development. As nodes of the network, cities are mutual symbiosis and prosperity. Together with the network, the cooperative relationship between cities has led to the increasing degree of specialization and the deepening of urban division [18]. In the regional city network, cities share the resources and markets of the whole region, and thus enhance the attraction of enterprises and individuals by using each other's ad- 
vantages. The result is that it strengthens the agglomeration effects [19]. Under these influences, the reconstruction, optimization and upgrading speed of urban economic structure is faster than the way of relying solely on the strength of the city itself.

2) The impact on innovation. The city Network has two effects on innovation.

(1) The city network itself has multiple network attributes such as industry, finance, $R \& D$, innovation, service, transportation, technology and information. As nodes of the multiply interactive overlay network, cities have formed a more comprehensive and open platform of sharing resources, information. The platform is conducive to the innovation capacity of the new knowledge, new technologies, new products and other aspects. It could also decrease the uncertainty of urban development [20] [21] [22]. (2) In the current urban economy, knowledge, information, services and innovation gradually replace the traditional raw materials, capital and labor as the key elements of production. According to the theory of interlocking city network, the interlocking city network is formed when the "flows" flow between cities for the purpose of providing capital or professional ideas, information. In other words, the "urban flows" that carry the knowledge elements which are different from the traditional resource-based elements and have the characteristics of increasing marginal returns [23] not only disseminate knowledge and innovation to every city in the network, but also provide a rich and varied knowledge of the soil for innovation, thereby expanding the spread of new knowledge, new technology, and spillover effects. In addition, the mechanism of rapid absorption and feedback in the city network has interlocking and superposed effects on the update and dissemination of new knowledge, new technology and new product. Furthermore, the deepening urban division also has a strong effect on the improvement of urban innovation ability. Cities can be more effective in knowledge accumulation and creation due to the specialization of innovation.

3) Network externality and spillover effect

In the collaborative city network, cities can obtain the economies of scale of " 1 $+1>2$ " and the spillover effects of other cities. This is demonstrated in the study of 'Healthy City Network' of the World Health Organisation, and it is found that the collaborative network could improve administrative efficiency of governments [24]. Moreover, the more positive the attitude of the participants, the better the effects. It is also found that the interlocking city network has a significant effect on the promotion of urban competitiveness [25]. In the process of collaboration, the methods that cities invent to improve economic and managerial efficiency spread in the network and benefit the other cities.

In general, while the city network impacts urban specialization, agglomeration effects, industrial structure, innovative technology, administrative efficiency and other attributes, thereby leading to rapid and uninterrupted changes of the operation mode of the city, it also improves the efficiency through the network externality and spillover effects. These effects not only change the internal attribute factors that determine the optimal city size, but also change the organization 
mode of the factors and their relative importance in deciding the optimal size. The Formula (2) can represent the decision mechanism of the optimal city size from the perspective of city network.

$$
N^{*}=A f(n) E_{1}^{\alpha_{1}} E_{2}^{\alpha_{2}} \cdots E_{m}^{\alpha_{m}}
$$

In the formula above $n$ represents the external network factor and $f(n)$ is the way $n$ impacts on the optimal city size. The internal attribute factors and the external network factor together construct the decision conditions of the optimal city size.

The $N^{*}$ in Formula (2) is the optimal city size at a certain instantaneous point. At the moment, the internal and external factors and their organization mode are determined, so the optimal city size is also a determined value. When time moves to another point, that is to say when the city's internal and external properties change, the optimal city size will also come to the corresponding value. Considering that the internal attribute factors are affected by external network factor, this change has a characteristic, that is $\Delta E_{i}$ and $n$ are related. The $\Delta E_{i}$ represent the differences of one of the internal factors at the two points. However, we can't bring this change directly into the formula, only by comparing the optimal size at the two points to discover the roles of the internal and external factors in the process.

\section{Conclusion}

Most of the existing researches on optimal city size start from the perspectives of the competition based on the urban hierarchy model. In order to seek the optimal size of the city under the reaction of internal properties and organizational mode at a single point of time, those researches examine the economic behaviors of the firms, individuals and governments from the perspective of a single city. This analysis process ignores the external environment of the city network which is characterized by urban cooperation. In other words, this process internalizes the urban network into internal variables that have the same status as other internal properties [26]. At present, when the city network has increasingly become the main way of urban development, the optimal city size from the traditional perspective deviates from the realities to some extent. Based on this, this paper starts from the essential concept of optimal city size and analyzes the influences of urban network on urban production and internal attribute characteristics. In addition, this paper also briefly analyzes the influence path and mechanism of urban network on the optimal city size.

Proposal of the optimal city size concept essentially provides a basis for more efficient operation of the city. The optimal size of a single city is determined by internal properties and organizational mode of the city. Considering the formation and development of the city network and the influence on the urban production operation, the optimal city size is determined together by the internal and external factors and their organizational mode. Specifically, the city's external network factor and internal properties build a new urban operating system. 
Under this system, the urban division-based urban network factors strengthen the city's agglomeration economy, optimize the industrial structure, achieve the optimal allocation of old and new factors of production, and improve urban innovation and its spillover effect with a broad knowledge of information networks; At the same time, network externality and network spillover effects further change the way in which a city operates.

Based on the discussion above, it can be clearly found that when the urban policy is formulated, it is difficult to obtain the policy objective aimed at pursuing a suitable city size by ignoring the dynamic impact of the urban network on the optimal city size and simply judging the actual scale deviation from the single city itself. In the detection of whether the city is efficient, just examining the size is too large or too small is not enough, more importantly, whether the internal and external system is running healthily needs to be found. If not, then it needs to know which part of the system is the problem and pull it back on track which is corresponding to the optimal city size.

\section{Discussion}

It is necessary to point out that this paper is only a brief analysis. Thus, further theoretical and empirical discussions are required. Those discussions are especially embodied in the following two aspects: Firstly, as the influences of city network on the optimal city size is realized by promoting changes of the urban developmental mode, its mechanism should be a dynamic interlocking system from micro to macro. The direct and indirect influences of urban network on optimal city size are only a preliminary theoretical discussion in this paper. As for real examples, although some scholars have proved that urban network has a positive effect on improving the urban economic efficiency [27] [28] [29], those statistical studies are conducted under the framework of a single city model, which lack micro-mechanism analysis of the city network to the urban production and organization. In the theoretical model of the single optimal city size, the new economic geography combines the individual utility optimization, the maximization of the firm's efficiency and the total efficiency of the city. Thus, a relatively complete micro and macro theoretical system is formed. However, from the perspective of the urban network, due to lack of micro-mechanism (most of scholars macroscopically examine the network characteristics of city network and the hierarchical status of cities in the network, and few pay attention to the micro-impact mechanism of urban network), the theoretical system is far from forming. Before making clear the microscopic mechanism of the urban network, it may not be appropriate to directly apply or improve the existing theoretical model based on optimal size of a single city.

Theoretically, the city network has changed the way in which the city develops. Thus, determinate conditions of the optimal city size are also changed accordingly. However, considering the fact that the city itself is also an organic complex system, the influences of the city network on the city operation and then on the optimal city size is a systematic mechanism. Although this mechan- 
ism is slightly spied upon above, it is still much simpler than the actual situation. This is because a change in the characteristics of a city's properties may cause dynamic interlocking reaction of the city itself and properties of other cities in the network. And this dynamic interlocking reaction becomes more complex and difficult to track, as the urban network and the urban properties affected each other.

Secondly, the impact way and extent of the city network on the optimal size of different nodal cities should be heterogeneous. Additionally, the difference between the actual size and the optimal size should also be impacted differently. In general, cities with higher status in urban networks tend to carry more services throughout the network, while lower-level cities are more specialized in production or act as service centers for a special industry. And from the perspective of differential urban innovation, cities with higher status in urban networks often play the role of innovational source, while the lower-level cities often more play the role of receivers of innovational spillovers. Therefore, the optimal sizes of the cities with different network status and nodal functions are impacted by the city network in different ways and to different extents.

Inside the city network, especially inside the regional city network with high development maturity, due to the close intercity link, dense intercity transportation network, frequent intercity flow of population and information, and the relative public, symmetrical and transparent intercity cost and income-related information, the enterprises are facilitated to make more accurate decisions regarding site selection. And people are much easier to make a rational decision on selection of workplace and residence. It can achieve inter-city migration in the region at a lower cost, thus greatly improving the city's ability of self-regulation towards the optimal size and making the actual size of the city closer to the optimal size. The more maturely the regional urban network develops, the lower the degree of deviation should be.

\section{References}

[1] Henderson, J.V. (1974) The Sizes and Types of Cities. The American Economic Review, 64, 640-656.

[2] Richardson, H. (1972) Optimality City Size, Systems of Cities and Urban Policy, A Sceptic's View. Urban Studies, 9, 29-48. https://doi.org/10.1080/00420987220080021

[3] Alonso, W. (1971) The Economics of Urban Size. Papers of the Regional Science Association, 26, 67-83. https://doi.org/10.1111/j.1435-5597.1971.tb01493.x

[4] Wang, X.L. and Xia, X.L. (1999) Optimizing City Size, Promoting Economic Growth. Economic Research Journal, 9, 22-29.

[5] Zheng, X. (2007) Measurement of Optimal City Sizes in Japan, A Surplus Function Approach. Urban Studies, 44, 939-951. https://doi.org/10.1080/00420980701318961

[6] Arnott, R. (1979) Optimal City Size in a Spatial Economy. Journal of Urban Economics, 6, 65-89.

[7] Arnott, R. and Stiglitz, J. (1979) Aggregate and Rents, Expenditure on Public Goods, and Optimal City Size. The Quarterly Journal of Economics, 93, 471-500.

https://doi.org/10.2307/1884466 
[8] Arnott, R. (2004) Does The Henry George Theorem Provide a Practical Guide to Optimal City Size? The American Journal of Economics and Sociology, 63, 10571090. https://doi.org/10.1111/j.1536-7150.2004.00334.x

[9] Kanemoto, Y., Ohkawara, T. and Suzuki, T. (1996) Agglomeration Economies and a Test for Optimal City Size in Japan. Journal of the Japanese and International Economies, 10, 379-398. https://doi.org/10.1006/jjie.1996.0022

[10] Duranton, G. and Puga, D. (2003) Micro-Foundations of Urban Agglomeration Economies. Working Paper 9931, NBER.

[11] Camagni, R., Diappi, L. and Stabilini, S. (1994) City Networks in the Lombardy Region: An Analysis in Terms of Communication Flows. FLUX, 15, 37-50. https://doi.org/10.3406/flux.1994.975

[12] Taylor, P.J. (2001) Specification of the World City Network. Geographical Analysis, 33, 181-194. https://doi.org/10.1111/j.1538-4632.2001.tb00443.x

[13] Taylor, P.J. (2004) Regionality in the World City Network. International Social Science Journal, 56, 361-372. https://doi.org/10.1111/j.0020-8701.2004.00499.x

[14] Taylor, P.J., Hoyler, M. and Verbruggen, R. (2010) External Urban Relational Process: Introducing Central Flow Theory to Complement Central Place Theory. Urban Studies, 47, 2803-2818. https://doi.org/10.1177/0042098010377367

[15] Taylor, P.J. and Walker, D.R.F. (2001) World Cities: A First Multivariate Analysis of Their Service Complexes. Urban Studies, 38, 23-47. https://doi.org/10.1080/00420980125400

[16] Derudder, B., Taylor, P.J., Witlox, F., et al. (2003) Hierarchical Tendencies and Regional Patterns in the World City Network: A Global Urban Analysis of 234 Cities. Regional Studies, 379, 875-886. https://doi.org/10.1080/0034340032000143887

[17] Brown, E.D., Derudder, B., Parnreiter, C., et al. (2010) World City Networks and Global Commodity Chains: Towards a World-Systems' Integration. Global Networks, 10, 12-34. https://doi.org/10.1111/j.1471-0374.2010.00272.x

[18] Arndt, O. and Sternberg, R. (2000) Do Manufacturing Firms Profit from Intraregional Innovation Linkages? An Empirical Based Answer. European Planning Studies, 8, 465-485. https://doi.org/10.1080/713666423

[19] Meijers, E. (2005) Polycentric Urban Regions and the Quest for Synergy, Is a Network of Cities More than the Sum of the Parts? Urban Studies, 42, 765-781. https://doi.org/10.1080/00420980500060384

[20] Eraydin, A. and Armatli-Köroğlu, B. (2005) Innovation, Networking and the New Industrial Clusters: The Characteristics of Networks and Local Innovation Capabilities in the Turkish Industrial Clusters. Entrepreneurship \& Regional Development, 17, 237-266. https://doi.org/10.1080/08985620500202632

[21] Boix, R. and Trullén, J. (2007) Knowledge, Networks of Cities and Growth in Regional Urban Systems. Papers in Regional Science, 86, 551-574. https://doi.org/10.1111/j.1435-5957.2007.00139.x

[22] Breschi, S. and Lenzi, C. (2016) Co-Invention Networks and Inventive Productivity in US Cities. Journal of Urban Economics, 92, 66-75.

[23] Cheng, Y.H. and Chen, L.J. (2012) Deconstruction of Urban Competitiveness from the Perspective of Urban Network. Economist, 8, 72-79.

[24] Capello, R. (2000) The City Network Paradigm, Measuring Urban Network Externalites. Urban Studies, 37, 1925-1949. https://doi.org/10.1080/713707232

[25] Cheng, Y.H. and Cheng, L.Y. (2014) The Research about Sources of City Competitiveness Based on the Perspective of Cities Competition and Cooperation-Taking 
the Greater Pearl River Delta as an Empirical Case. Economist, 9, 50-57.

[26] Camagni, R., Capello, R. and Caragliu, A. (2013) One or Infinite Optimal City Size? In Search of an Equilibrium Size for Cities. The Annals of Regional Science, 51, 309-341. https://doi.org/10.1007/s00168-012-0548-7

[27] Zheng, X. (2007) Economies of Network, Urban Agglomeration, and Regional Development: A Theoretical Model and Empirical Evidence. Regional Studies, 41, 559569. https://doi.org/10.1080/00343400701281774

[28] Qin, C.L. and Sang, M.C. (2015) Urban Network and Urban Economic Growth. Study and Practice, 4, 5-11 + 2 .

[29] Zhan, Y.B. and Hou, S.H. (2015) An Analysis of the Impact of Urban Network Effect on Economic Growth in China. Journal of Commercial Economics, 23, 51-53.

Submit or recommend next manuscript to SCIRP and we will provide best service for you:

Accepting pre-submission inquiries through Email, Facebook, LinkedIn, Twitter, etc. A wide selection of journals (inclusive of 9 subjects, more than 200 journals)

Providing 24-hour high-quality service

User-friendly online submission system

Fair and swift peer-review system

Efficient typesetting and proofreading procedure

Display of the result of downloads and visits, as well as the number of cited articles

Maximum dissemination of your research work

Submit your manuscript at: http://papersubmission.scirp.org/

Or contact jss@scirp.org 